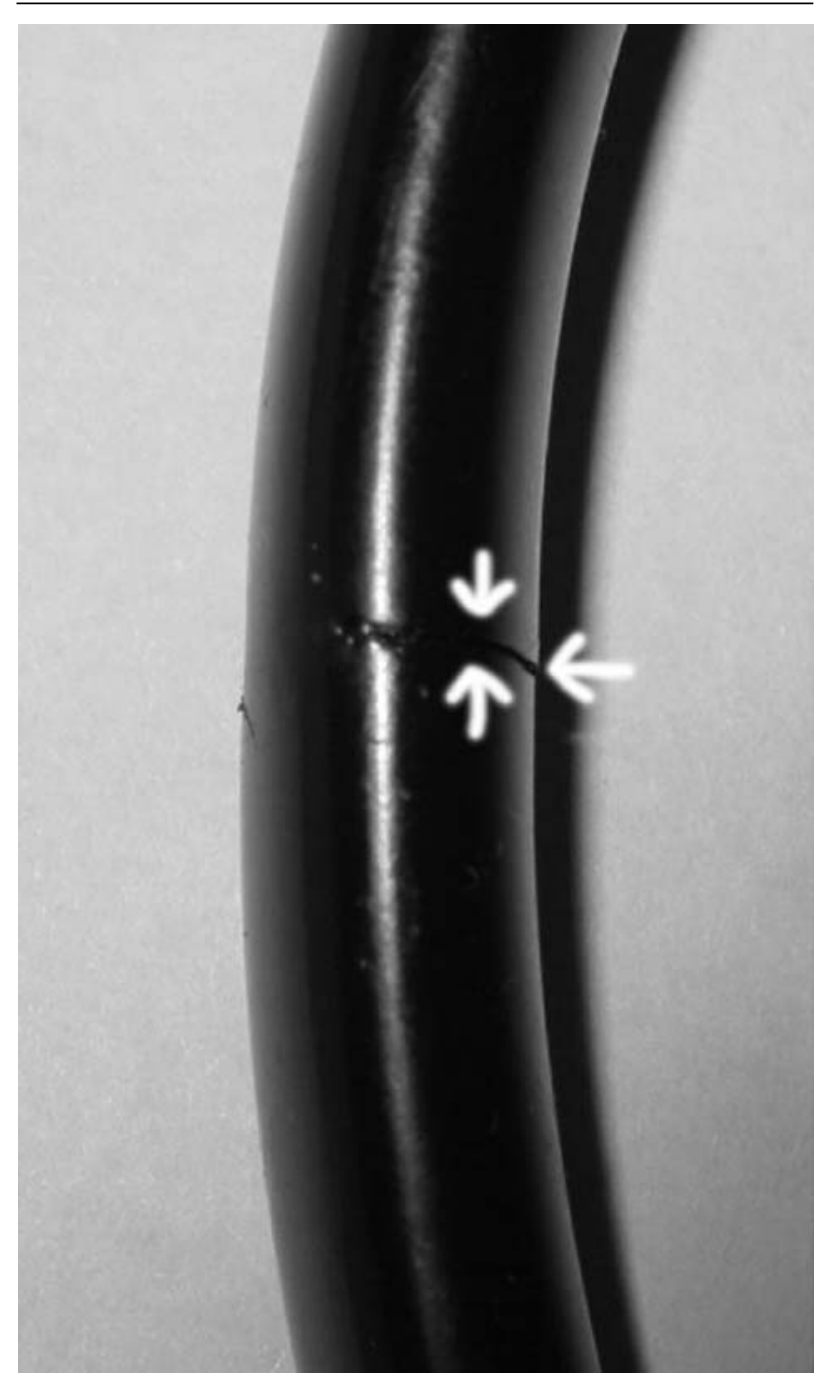

FIGURE 1 Hairline fracture of tubing marked with arrows.

point, a problem with the stethoscope was suspected, and auscultation with a different stethoscope confirmed that air entry was equal bilaterally. The case proceeded uneventfully.

Upon initial inspection, the stethoscope in question (Littman, Cardiology II S.E., age approximately eight years) appeared to be intact and undamaged. Upon extension of the plastic tubing and closer inspection, the tubing was seen to be cracked, and nearly transected midway along its length. With the tubing flexed/curled, the edges of the crack remained approximated and the stethoscope appeared to function normally (Figure 1). When the tubing was straightened or extended, the edges of the crack separated, and nothing could be heard (Figure 2). The

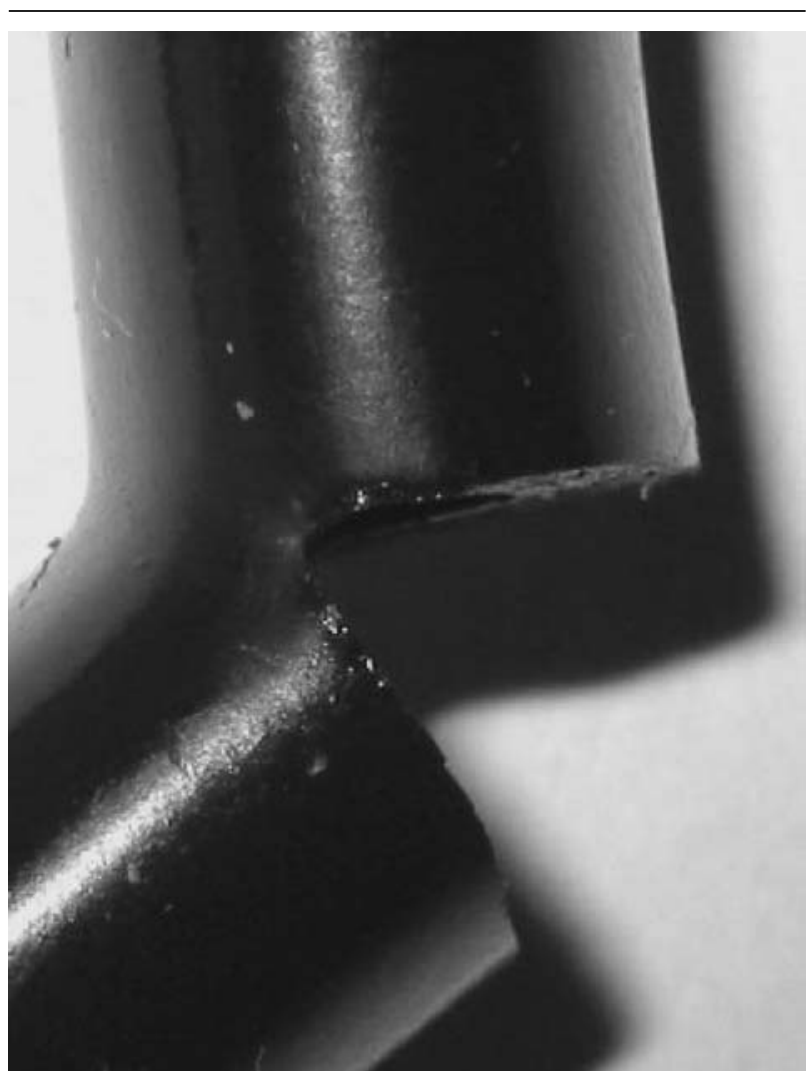

FIGURE 2 Tubing separation with auscultation.

stethoscope had been functioning normally the previous day, and no snapping or cracking sound indicating damage was heard. We are not aware of any previous report of the sudden cracking of a stethoscope's tubing, and this was confirmed with a Medline search. Just as the anesthetic machine is checked on a daily basis, our other equipment must also be examined regularly in order to detect damage or malfunction, which can occur at any time.

Arie Peliowski MD

Chris Christodoulou MB CHB

Winnipeg, Manitoba

\section{Propofol decreases cerebral blood flow velocity in anesthetized children}

To the Editor:

In the October issue of the Journal, Karlsi et al., ${ }^{1}$ published the results of a study examining differences in middle cerebral artery flow velocity (CBFV) in chil- 
dren receiving low dose $v s$ high dose propofol infusion for urologic surgery. Examining the dose related effect of propofol on CBFV in children is important to our understanding of the differences in cerebrovascular responses between children and adults. However, no details about the age distribution of children in each of the randomized groups are presented, nor are differences in age between the two groups described. This is relevant because CBFV changes with age. ${ }^{2}$ The data appear to have been analyzed without consideration for the age-related differences in CBFV. We recognize that there are only six children in each group. Nevertheless without this information it is difficult to determine whether the difference in CBFV between the low dose and high dose propofol groups are valid for children between one and six years of age.

Monica S. Vavilala MD

Arthur M. Lam MD FRCPC

Seattle, Washington

\section{References}

1 Karsli C, Luginbuebl I, Farrar M, Bissonnette B. Propofol decreases cerebral blood flow velocity in anesthetized children. Can J Anesth 2002; 49: 830-4.

2 Bode H. Pediatric Applications of Transcranial Doppler Sonography. New York: Springer-Verlag; 1988: 114.

REPLY:

We would like to thank Drs. Vavilala and Lam for their interest and comments regarding the effects of propofol on cerebral blood flow velocity (CBFV) in children. ${ }^{1}$ The suggestion that $C B F V$ changes with age is an accurate one, although the most rapid changes occur outside of the age range of our patient population. From birth to 18 months CBFV increases rapidly, followed by a much slower increase to peak values at around seven years of age. ${ }^{2}$ As such, the age range of our study patients was in fact chosen in order to minimize age-related effects on CBFV, and we are confident that the analysis reported the variation in CBFV in response to propofol dosing, rather than age-related factors. The coefficient of variation was found to be well within acceptable values, suggesting that variability in CBFV was not likely due to age-related effects.

Cengiz Karsli BSC MD FRCPC

Bruno Bissonnette BSC MD FRCPC

Igor A. Luginbuehl MD

Toronto, Ontario

\section{References}

1 Karsli C, Luginbuehl I, Farrar M, Bissonnette B. Propofol decreases cerebral blood flow velocity in anes- thetized children. Can J Anesth 2002; 49: 830-4

2 Bode H. Methods: recording technique. In: Bode $\mathrm{H}$ (Ed.). Paediatric Applications of Transcranial Doppler Sonography. New York: Springer-Verlag; 1988; 21-2, 114.

\section{High-degree atrioventricular block after the administration of atropine for sinus arrest during anesthesia}

To the Editor:

We describe a case of sudden sinus arrest of six seconds' duration under general anesthesia in a patient with preoperative asymptomatic bifascicular block. Atropine $0.5 \mathrm{mg}$ was ineffective in resolving the sick sinus syndrome, and the arrhythmia progressed to atrial flutter with high-degree atrioventricular block.

A 77-yr-old man with chronic renal failure was admitted for construction, under general anesthesia, of an arteriovenous fistula by compound vascular graft for hemodialysis. His electrocardiogram (ECG) showed complete right bundle branch block with left axis deviation. Anesthesia was induced with thiamylal $150 \mathrm{mg}$, vecuronium $6 \mathrm{mg}$, and fentanyl $0.1 \mathrm{mg} i$. A mixture of $50 \%$ oxygen, $50 \%$ nitrous oxide, and approximately $0.8 \%$ isoflurane was given for maintenance of anesthesia. Sinus arrest of six seconds' duration occurred $110 \mathrm{~min}$ after induction. Intravenous atropine $0.5 \mathrm{mg}$ was administered immediately but was ineffective, and his ECG showed progression to atrial flutter with high-degree atrioventricular block (Figure). Thereafter, $1 \mathrm{mg}$ of epinephrine $i v$ was given and sinus rhythm was restored.

Sick sinus syndrome has been reported after spinal anesthesia ${ }^{1}$ and after induction of general anesthesia. ${ }^{2}$ The authors of these two reports suggested that the balance between sympathetic and parasympathetic tone is important in the maintenance of heart rate. Parasympathetic tone appeared to be predominant in our patient. General anesthesia was induced primarily to relax the patient during a surgical procedure of long duration. Thus, an imbalance in the autonomic nervous system may have resulted in sinus arrest.

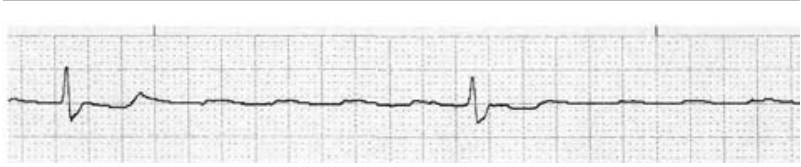

FIGURE The rhythm strip displays atrial flutter with highdegree atrioventricular block, which appeared after treatment with atropine. 